\title{
Does Poverty and Emotional Trauma in Children Affect their Mental Health?
}

\author{
Richard J Nichol* \\ Department of Psychiatry, University of the Free State, South Africa \\ *Corresponding author: Richard J Nichol, Department of Psychiatry, University of the Free State, South Africa \\ Submission: December 20, 2017; Published: April 02, 2018
}

\section{Introduction}

This may seem like a rhetorical question, but three very different opinions regarding poverty and psychopathology can be identified in the large volume of literature on this topic. Most literature available links the multiple stressors associated with poverty to an elevated risk of developing mental illness. Even if the cycle of poverty is broken, lasting psychiatric sequelae remain. Some researchers [1] acknowledge the psychiatric effects of chronic stress factors associated with poverty, deprivation and neglect, but claim lower rates of after- effects of mental illness are evident once families move into more advantageous living conditions. Alternatively Tampubolon \& Hanadita [2] claim poverty is not likely to have much influence on mental health in India and Indonesia at all.

This survey of the literature, (although not exhaustive) however focuses mainly on the first theme detailing the psychiatric effects of deprivation and neglect rather than concentrating on the neurodevelopmental effects of poverty which have been well studied for many years. Strategies to help individuals and communities are also briefly discussed.

\section{Understanding poverty}

Poverty is regarded by The World Bank as a multidimensional social phenomenon. Hatton et al. [3] follow the classic Townsend approach to defining relative poverty as individuals or families who are unable 'due to lack of resources', to participate in society and to enjoy a standard of living consistent with human dignity and social decency.

In a similar manner the Scottish Poverty Information Unit regards poverty as relative to the standards of living in a society at a specific time. People live in poverty when they are denied an income sufficient for their material needs and when these circumstances exclude them from taking part in activities which are an accepted part of daily life in that society [4].

According to the Bristol Study: Of the 1,8 billion children in the developing countries, $15 \%$ of children under five were severely food deprived accounting for half the deaths of children under the age of five due to malnutrition [5]. $20 \%$ of children did not have access to safe drinking water while $31 \%$ did not access to adequate sanitation facilities. 500 million children (34\%) did not have adequate shelter. 134 million children aged 7 to 18 , (13\%), had never been to school.

The World Bank states the most common way to measure poverty is based on incomes. A person is believed to be poor if his or her income falls below some minimum level (known as the poverty line), necessary to meet basic needs. There are two main subsections namely the relative and the absolute poverty lines [6].

The Relative Poverty Line depends on the income distribution within a given country and varies according to purchasing power and is often set at $50 \%$ of a given country's mean income.

The Absolute Poverty Line (also called the extreme poverty line) is often determined according to the average cost of basic survival in the poorest 10-20 countries of the world, and previously referred to households earning less than $1 \$(\mathrm{US})$ per day. More recently this figure has risen to less than $2 \$$ (US) per day. In a similar light, in 2008 about one quarter of the world population was earning an income of less than 1.25 \$(US) a day. Most research into the effects of poverty relate to this category [7]. In the South African context, a monthly Child Support Grant of ZAR 330.00 per month equates to less than $1 \$$ /day per child. In many cases the household budget will also be increased by other members of the family receiving alternate grants [8].

The previous Prime Minister of Great Britain, David Cameron, has described a third aspect of poverty as being 'social exclusion' which he describes as a shorthand label for what can happen when individuals or areas suffer from a combination of linked problems such as unemployment, poor skills, low incomes, poor housing, high crime environments, bad health and family breakdown [4].

Fowler et al. [9] evaluated the effect of housing instability on children's behaviours. According to Shinn, approximately onefourth of all episodes of poverty in the United States of America begin with the birth of a child; pregnancy or the birth of a child is associated with the beginning episodes of homelessness [10]. Preschoolers and adolescents at risk for child abuse exhibited higher 
rates of externalizing behaviours over a period of three years when exposed to housing mobility than school-age children.

\section{Psychopathology}

In the USA, the Centers for Disease Control and Prevention (CDC) report that one in five children either currently or at some point during their lifetime will have had a seriously debilitating mental disorder but only about $20 \%$ of these youth receive treatment [11]. The percentage of children having access to adequate mental health care is far lower in developing nations [12]. Victims of childhood physical or sexual abuse or parental neglect are at considerably greater risk for affective disorders such as depression, especially as adverse childhood experiences are cumulative The magnitude of the risk for depression can be associated directly with the amount of different types of adversity to which an individual is exposed [13].

Bassuk et al. [10] reviewed 12 studies relating to homelessness in the United States of America. Overall 10 to $26 \%$ of homeless preschoolers had mental health problems. This proportion increased to 24 to $40 \%$ among homeless school-age children, a rate two to four times higher than other poor children aged six to nine years in the National Surveys of America's families.

In 2011, Park, Fertig and Allison [6] studied 5000 families in 20 different cities in the USA having a low income. The researchers noticed that homelessness and precarious living conditions were associated with more internalizing and externalizing problems among 3 year olds compared to their peers living in more stable environments. Najman and co-workers conducted a longitudinal study in Australia to determine the effects of poverty on child development. Subjects who had been exposed to poverty in utero, at 18 months of age, at 5 years and at 14 years, were all associated with increased rates of anxiety and depression in adolescence and early adulthood. The researchers realised that repeated experiences of poverty were directly associated with poorer mental health outcomes [6].

In New Zealand Caspi et al. followed a group of 440 young males from birth to the age of 26 years. Violent behaviour, Conduct Disorder, and Anti- social Personality Disorders (APD) were associated with abusive situations that had occurred before they had reached the age of 11 years [14].

According to Baker et al. [15], having a criminal birth parent increases one's own risk of having a criminal conviction as an adult, regardless of if the person was raised by pro-social and law-abiding but genetically unrelated foster parents.

\section{Poverty and emotional trauma as chronic stressors to the developing brain}

This mechanism is not clearly understood, but 3 factors should be considered: Firstly the stimulation of the hypothalamic- pituitaryadrenal axis (HPA). The body is geared to coping physiologically in stressful situations in order to survive with several body systems in place including the sympathetic and parasympathetic (autonomic) nervous system, the HPA, neurotransmitter systems and the immune systems. There are individual variations in the thresholds above which an individual perceives an experience to be stressful and in the response to the stress. These individual differences in stress responsiveness are partly genetically determined and partly based on prior experiences [16].

Children who have been exposed to various traumatic stressful situations previously, (with increased stress responsiveness), are innately more reactive to stress and are therefore more vulnerable to its consequences. It has been found that during the first year of life, there is a progressive decrease in cortisol responsiveness to stress, returning to the subsequent response early in early childhood which apparently buffers the brain from the harmful effects of cortisol [16]. This dampening of the cortisol stress response does not occur in infants who have received insensitive and unresponsive caregiving. Babies having negative emotional temperaments with poorer self-regulation skills are particularly vulnerable. Severe stress during the sensitive (critical) periods of neurodevelopment has a long-lasting organizing effect on the brain and the stress axes. Child abuse and neglect often exert a cumulative harmful effect on neuroendocrinological development which persists into adulthood [17]. Elevated CSF levels of Corticotropin-releasing Factor have been detected young adults living in these circumstances Anacker et al. [13].

Secondly, regions in the brain with a high density of glucocorticoid receptors are particularly vulnerable to adversity. Excessive stress levels in childhood are associated with architectural changes in the developing brain including in: the amygdalae, hippocampus, cerebellar vermis, the prefrontal cortex, and the corpus callosum [17], which are involved in emotional experience, stress regulation, learning and the ability to cope with adversity. Cortisol also suppresses glial cell division reducing myelinization of the brain. Brain imaging studies have documented long-lasting changes in brain structures and functions associated with memory, executive control, reward, sensory, and affective processing in individuals having a history of early life adversity. Puetz and coworkers [18] focussed on examining the effects of early life stress (ELS) in children that had been separated from their caregivers. On a neural level, children with ELS showed reduced activation in the dorsal anterior cingulate cortex (dACC), and dorsolateral prefrontal cortex (dIPFC), and reduced connectivity between dIPFC- dACC, areas previously implicated in affect regulation. These children showed increased neural activation in brain regions involved in memory, arousal, and threat related processing (middle temporal gyrus, thalamus, and ventral tegmental area).

Thirdly theories concerning epigenetics, a term coined by Sir Conrad Waddington some 70 years ago. His theories have proven to be fundamental in abolishing 'ínstincts' and genetic 'programmes' [19-21], describe epigenetics as the interaction between genes and the environment that give rise to a specific phenotype.

Epigenetic processes havelong been recognized as indispensible for appropriate embryonic and early postnatal development [21]. 
As research in this field has continued it is now apparent that these same mechanisms that drive critical processes in development and in mitotic throughout the lifespan remain dynamic in neurons that once differentiated are incapable of mitosis. Also apparent is the theory concerning the dynamic DNA methylation and demethylation and enzymes responsible for methylating or demethylating DNA, which are critically involved in memory formation and behavioural plasticity [21].

The measured gene/ measured environment approach may be used to investigate the main effects of both genes and environment, or to understand more complex interactions whereby environments may moderate genetic effects or vice versa. In 2006 Rutter and co-workers noted a key principle in modern research on developmental psychopathology suggests that psychopathology and individual differences in normal development are the joint products of both biological and social influences [22]. Theories of person-environment describe how peoples' behaviour, personality or cognitive abilities shape their environment. Epigenetic regulation of multiple physiological systems that contribute to disease risk is a likely candidate for persistent changes in metabolic and brain function as a consequence of the perinatal environment [23].

When researchers examined the DNA of 40 boys from major US cities at the age of nine years, they found the telomeres of children from harsh home backgrounds were 19\% shorter compared to children living in more favourable home situations. The length of the telomeres is considered to be a biomarker of chronic stress [24]. The DNA of the participants taking part in the Fragile Families and Child Wellbeing study of the US National Institute of Health was studied. This study involved nearly 5000 children born in the years 1998 to 2000 to unmarried parents in various US cities. The telomeres of boys whose mothers had completed secondary education were $32 \%$ longer than those of boys whose mothers had not completed high school. Like-wise the telomeres of children living in a stable environment were $40 \%$ longer than those of children living in unstable families where the parent had multiple partners [24].

Although not unique to poverty, teenage childbearing is internationally recognized as a public health problem associated with a range of risks for both young mothers and their children [7,24]. Adolescence is a transitional period marked by social, psychological and biological changes, and childbearing during this period interferes with normative developmental processes. Teenage childbirth often disrupts young mothers' educational achievement and limits employment opportunities increasing their risk for substance abuse, mental health care problems and criminal convictions later in life often aggravating the cycle of poverty. In turn the offspring born to these young mothers also experience poor developmental outcomes, including low birth weight, preterm delivery, and behavioural and developmental problems. An association between the offspring of adolescent mothers and antisocial behaviour was found in a Swedish study conducted by Coyne and co-workers [25]. However, there was little evidence for genetic confounding due to passive gene-environment correlation. It remains unclear if maternal age at first birth is causally associated with offspring antisocial behaviour or if this association is due to selection factors that influence both the likelihood that a young woman gives birth early and that her offspring engage in antisocial behaviour [25].

\section{Case example}

I have found Bongile's triumphs over poverty to be most inspiring. As happens in many South African families, Bongile's father deserted them, leaving his (ex) wife to raise three children. Sadly after his mother's tragic death (HIV related), Bongile took charge of their 'child headed household' with meagre resources to survive on. He developed novel ways of finding food for his siblings including attending many funerals of strangers on Saturdays where food would be readily available for everyone present. He soon learned to ask the different groups at the cemetery if a sheep or an ox had been slaughtered to feed the mourners. If a sheep had been prepared, invariably there wouldn't be much food for everyone, however in the case of an ox having been cooked, he and his siblings would form part of the cortẻge in the transport provided, and enjoy a meal after the funeral at the home of the deceased. He instructed his siblings to eat as much as they could so that they would not be too hungry the next week! Afterwards they would sometimes have to walk many kilometres to get home. Their elderly neighbours provided food for the three children when they were able. Bongile's dream was to become a surgeon one day. In spite of not having financial support and above average grades, his resilience, faith and persistence paid off and he was given an opportunity to study medicine. With the help of bursaries and benefactors he passed each academic year comfortably and graduated in due course. He plans to start as a registrar (resident) in surgery soon. Sadly Bongile's sister became pregnant and dropped out of school. Perhaps she will never be able to escape from the cycle of poverty without his help.

\section{Therapeutic approaches to help families to move out of poverty}

Despite significant barriers to obtaining mental health care, research shows that individuals with low incomes show significant benefit from evidence-based mental health care [26]. By addressing co-morbid medical illnesses and managing psychiatric conditions such as Major Depression and Post Traumatic Stress Disorder, individuals living in poverty can be in a stronger position to address other pertinent stress factors in their lives. Evidence suggests various forms of psychotherapy such as Cognitive-behavioral Therapy and Interpersonal Therapy are effective.

Family Therapy should also be considered to bolster individual and group resilience in the face of chronic stress. Warm nurturing families tend to promote resistance to stress, build resilience and diminish vulnerability to stress related illness. This process is often complicated when dealing with children whose families are dysfunctional or incomplete. 


\section{Interventions to reduce poverty and its effects on children}

Yoshikawa et al. [7] describe two approaches. Firstly a set of interventions which targets mediating mechanisms, and strives to prevent the mental, emotional and behavioural complications of poverty as described previously in this article. The second set of interventions relates to reducing poverty itself. Lund et al. [27] maintain that there is growing international evidence to show that mental ill health and poverty interact in low-income and middle income countries in a negative cycle. In reviewing the pertinent literature, two principal causal pathways were postulated:

a) According to the social causation hypothesis, conditions of poverty increase the risk of mental illness through heightened stress, social exclusion, decreased social capital, malnutrition, and increased obstetric risks, violence and trauma. Ways of breaking the cycle would include financial assistance in the form of cash transfers, microfinance, loans and debt counselling.

b) The social selection or social drift hypothesis supposes that people with mental illness are at increased risk of drifting into or remaining in poverty through increased health expenditure, reduced productivity, stigma and loss of employment and associated earnings. Interventions to improve the standard of mental health care would be used to alleviate poverty.

\section{The effects of artificial financial manipulation as poverty reducing strategies}

The use of artificial financial manipulation as a poverty reducing strategy is explained by Osypuk et al. [28]. The Moving to Opportunity (MTO) study describes how a selected group of people living in an area with high concentration of poverty (in one of five designated cities in the USA) received coupons to help them relocate from low income communities to lower income communities. The study also had a control group who were not moved and so remained in their low income community. The adolescent girls in the study who had not been the victims of crime prior to the experiment benefitted from the MTO's social engineering. On the other hand, male adolescents whose families had experienced crime victimization experienced worse distress, more behavioural problems and non-significant major depressive disorders than controls.

In line with the social causation hypothesis Crick et al. (2011), describe the effects of the financial interventions in four countries: In Mexico child beneficiaries of the Opotunades programme showed decreased reductions in the problem behaviour indices, but improvement in cognitive assessments, which only became evident after five years. The South African intervention using small loans was associated with an increase in stress levels among all the participants six months after the end of the intervention as the recipients had to start paying back their loans! In Ecuador where unconditional loans formed part of the programme, no effects on children's cognitive and behavioural outcomes (or the caregivers depression indices), were apparent after two years. However the asset promotion programme in Uganda reported positive effects in the self-esteem of school children. Both Yoshikawa et al. [7] and Copeland et al. [1] describe a 'natural experiment' where a casino was opened in the Eastern Cherokee Reservation, bringing financial relief to the families living there.

Copeland et al. [1] using data from the "The Great Smoky Mountains Study' argue that moving out of poverty reduces children's rates of behavioural psychiatric symptoms levels to levels similar to those who were never poor with no further consequences. This is a similar stance to the findings of Costello and co-workers published in 2003 [29]

\section{Conclusion}

As seen in this article, there is overwhelming evidence in the reviewed literature linking the effects of chronic stress (due to poverty, adverse living conditions and deprivation) to neuropsychopathology in children and adolescents.

Breaking the 'cycle of poverty' in most countries of the world still remains a daunting challenge due to the enmeshment of many factors (including labour markets, government policies, family efforts, political conflicts, physical and mental disabilities, social discrimination and unwise personal strategies), need to be addressed and remedied where possible.

Many government agencies, faith based organizations, Non Governmental Organizations (NGO's) and Non Profit Organizations (NPO's) should be commended for striving hard to alleviate poverty, but still there never seem to be enough resources available to help everyone. Mental health care workers certainly have a vital role to play in this process by not only treating psychopathology, but also by using preventative strategies which will increase resilience and promote the well-being of individuals and families in need.

Hopefully in future the emphasis will shift from not only alleviating poverty, but also to the utilization of measures to protect the developing brains of young children in line with (WHO) UNICEF's Millennium Developmental Goals [30-38].

\section{References}

1. Copeland WE, Angold A, Shanahan L, Costello EJ (2014) Longitudinal Patterns of Anxiety From Childhood to Adulthood: The Great Smoky Mountains Study. J Am Acad Child Adolesc Psychiatry 53(1): 21-32.

2. Tampubolon G, Hanadita W (2014) Poverty and mental health in Indonesia. Social science \& Medicine 106: 20-27.

3. Hatton C, Emerson E (2009) Poverty and the mental health of families with a child with intellectual disabilities. Psychiatry 8(11): 433-437.

4. British Broadcasting Corporation Home (2014) Wealth and Health Inequalities.

5. UNICEF (2006) Children Living in Poverty: Overview of Definitions, Measurements and Policies. United Nations Children's Fund (UNICEF), Global Policy Section, New York, USA 
6. Pacione L, Measham T, Kronick R, Meloni F, Ricard-Guay A, et al. (2012) The Mental Health of Children Facing Adversity, Poverty, Homelessness, War and Displacement. In: J Rey (Ed.), e-IACAPAP Textbook of Child and Adolescent Mental Health. International Association for Child and Adolescent Psychiatry and Allied Professions, Geneva, Switzerland, J 4 p. 1-31.

7. Yoshikawa H, Aber LA, Beardslee WR (2012) The Effects of Poverty on the Mental, Emotional, and Behavioral Health of Children and Youth. Am Psychol 67(4): 272-284.

8. SASSA (2015) Child Support Grant.

9. Fowler PJ, Henry DB, Schoeny M, Taylor J, Chavira D (2014) Developmental Timing of Housing Mobility: Longitudinal Effects of Externalizing Behaviors among At-Risk Youth. J Am Acad Child Adolesc Psychiatry 53(2): 199-208.

10. Bassuk EL, Richard MK, Tsertsvadze A (2015) The Prevalence of mmental Illness in Homeless Children: A Systematic Review and Meta=Analysis. Journal of the American Academy of Child and Adolescent Psychiatry 54(2): 86-96.

11. Joshi PT (2014) Presidential address: Partnering for the World's Children. Journal of the American Academy of Child and Adolescent Psychiatry 53(1): 3-8.

12. Becker AE, Kleinman A (2014) Mental Health and fthe Global Agenda. In: Raynaud JP et al. (Eds.), From Research to Practice in Child and Adolescent Mental Health. Rowman \& Littlefield. Lanham 1: 3

13. Anacker C, O'Donnell KJ, Meany MJ (2014) Early life adversity and the epigenetic programming of hypothalamic-pituitary-adrenal function. Dialogues Clin Neurosci 16(3) 321-333.

14. Cohen D (2012) The Developmental Being. Modelling a Probabilistic Approach to Child Development and Psychopathology. In: ME Garralda \& J Raynaud (Eds.), Brain, mind, and developmental psychopathology in childhood, Jason Aronson, Lanham.

15. Baker LA, Tuvblad C, Bezdjian S, Raine A (2012) Antisocial behavior gene-environment interplay. In: NurnbergerJr. JI, \& Berrettini WH (Eds.), Principles of Psychiatric Genetics. Cambridge University Press, Cambridge, UK, pp. 13: 148.

16. Glaser D (2012) The Effects of Child Maltreatment on the Developing Brain. In: M Elena Garralda \& Jean-Phillipe Raynaud (Eds.), Brain, mind, and developmental psychopathology in childhood. Jason Aronson, Lanham, pp. 199-218.

17. Panzer A (2008) The neuroendocrinological sequelae of stress during brain development: the impact of abuse and neglect. Afr J Psychiatry (Johannesbg) 1(1): 29-34

18. Puetz VB, Kohn N, Dahmen B, Zvyagintsev M, Schüppen A, et al. (2014) Neural Responses to Social Rejection With Early Separation Experiences. J Am Acad Child Adolesc Psychiatry 53(12): 1328-1337.

19. Renthal W. Nestler EJ (2012) Epigenetic mechanisms in drug addicition and depression. In JI Nurnberger Jr \& WH Berrettini (Eds.), Principles of Psychiatric Genetics, Cambridge University Press, New York, USA, p. 79-89.

20. Abel T, Poplawski S (2014) Guest Editorial -Epigenetic advances in clinical neuroscience. Dialogues Clin Neurosci 16(3): 273-290.

21. Morris MJ, Monteggia LM (2014) Role of DNA methylation and the DNA methyltransferase in learning and memory. Dialogues Clin Neurosci 16(3): 359-372.
22. Knafo A, Jaffee SR (2013) Gene-environmental correlation in developmental psychopathology. In: D Cicchetti (Ed.), Development and Psychopathology. Cambridge University Press, New York, USA, p: 1-6.

23. Bolton JL, Bilbo SD (2014) Developmental programming of the brain and behavior by perinatal diet: focus on inflammatory mechanisms. Dialogues Clin Neurosci 16(3): 307-320.

24. Madhusoodanan J (2014) Stress alters Children's genomes. Nature p. $1-3$

25. Coyne AC, Långström N, Rickert ME, Lichtenstein P, D’Onofrio BM (2013) Maternal age at first birth and offspring criminality: Using the children of twins design to test causal hypothesis. Dev Psychopathol 25(1): 1735 .

26. Santiago CD, Kaltman S, Miranda J (2013) Poverty and Mental Health: How do Low-Income Adults and Children fare in Psychotherapy. J Clin Psychol 69(2): 115-126.

27. Lund C, De Silva M, Plagerson S, Cooper S, Chisholm D, et al. (2011) Poverty and mental disorders: breaking the cycle in low-income and middle-income countries. Lancet 378 (9801): 1502-1514.

28. Osypuk TL, Schmidt NM, Bates LM, Tchetgen-Tchetgen EJ, Earls FJ (2012) Gender and Crime Victimization Modify Neighborhood Effects on Adolescent Mental Health. Pediatrics 130(3): 472-480.

29. Slopen N, Fitzmaurice G, Williams DR, Gilman SE (2010) Poverty, Food Insecurity, and the Behavior for Childhood Internalizing and Externalizing Disorders. J Am Acad Child Adolesc Psychiatry 49(5): 444-452.

30. Miranda JJ, Patel V (2005) Achieving the Millenium Developmental Goals: Does Mental Health Play a Role? Plos Med 2(10): e291.

31. Marlow M, Tomlinson M (2014) Child and Adolescent Services in Lowand Middle-Income Countries - The Role of Task Shifting. In J Raynard, et al. (Eds.), From Research to Practice in Child and Adolescent Mental Health. Rowman \& Littlefield, Lanham, pp. 103-123.

32. Bale TL (2014) Lifetime stress experience: transgenerational epigenetics and germ cell programming. Dialogues Clin Neurosci 16(3): 297-306.

33. Hall SS (2014) Behaviour and biology: The accidental epigenetist. Nature 505(7481): 14-17.

34. Hanson JL, Chung MK, Avants BB, Rudolph KD, Shirtcliff EA, et al. (2012) Structural Variations in Prefrontal Cortex Mediate in the Relationship between Early Childhood Stress and Spatial Working Memory. J Neurosci 32(23): 7917-7925.

35. Joshi PT, Daniolos PT, Salpekar JA (2010) Child Abuse and Neglect. In MK Dulcan (Ed.), Dulcan's Textbook of Child and Adolescent Psychiatry. American Psychiatric Publishing, Inc, Washington, DC, USA, pp. 479-494.

36. Kleintjes S, Lund C, Swartz L (2013) Barriers to the participation of people with psychosocial disability in mental health policy development in South Africa: a qualitative study of perspectives of policy makers, professionals, religious leaders and academics. BMC International Health and Human Rights 13(17): 1-10.

37. Rubinow D, Morris-Rosendahl (2014) Introduction. Dialogues in Clinical Neuroscience, In: Macher JM (Ed.), Epigenetics. 16(3): 269-270.

38. Tilleczek K, Fergusom M, Campbell V, Lezue KE (2014) Mental Health in Young Lives: Intersections and Directions. Canadian Journal of Community Mental Health 33(1): 63-76. 
Creative Commons Attribution 4.0 International License

For possible submissions Click Here

Submit Article

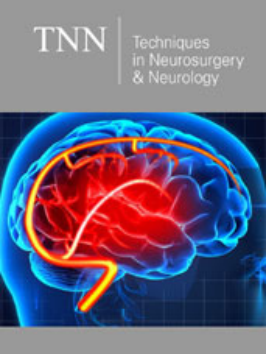

\section{Techniques in Neurosurgery \& Neurology}

Benefits of Publishing with us

- High-level peer review and editorial services

- Freely accessible online immediately upon publication

- Authors retain the copyright to their work

- Licensing it under a Creative Commons license

- Visibility through different online platforms 